Fausto Viana é figurinista, cenógrafo e pesquisador. Autor do livro 0 figurino teatral e as renovações do século XX e, juntamente com Rosane Muniz, organizador do livro Diário de pesquisadores: traje de cena. Doutor em Cenografia e em Museologia, e professor livre-docente da ECA-USP.

E-mail: faustoviana@uol.com.br

Rosane Muniz é pesquisadora, jornalista e atriz. Autora do livro Vestindo os nus: o figurino em cena. Doutoranda em Cenografia na ECA-USP, está reformulando o site www.vestindoacena.com.

E-mail: romuniz@gmail.com

\title{
Uma aventura no backstage do Cirque du Soleil: figurinos na corda bamba!
}

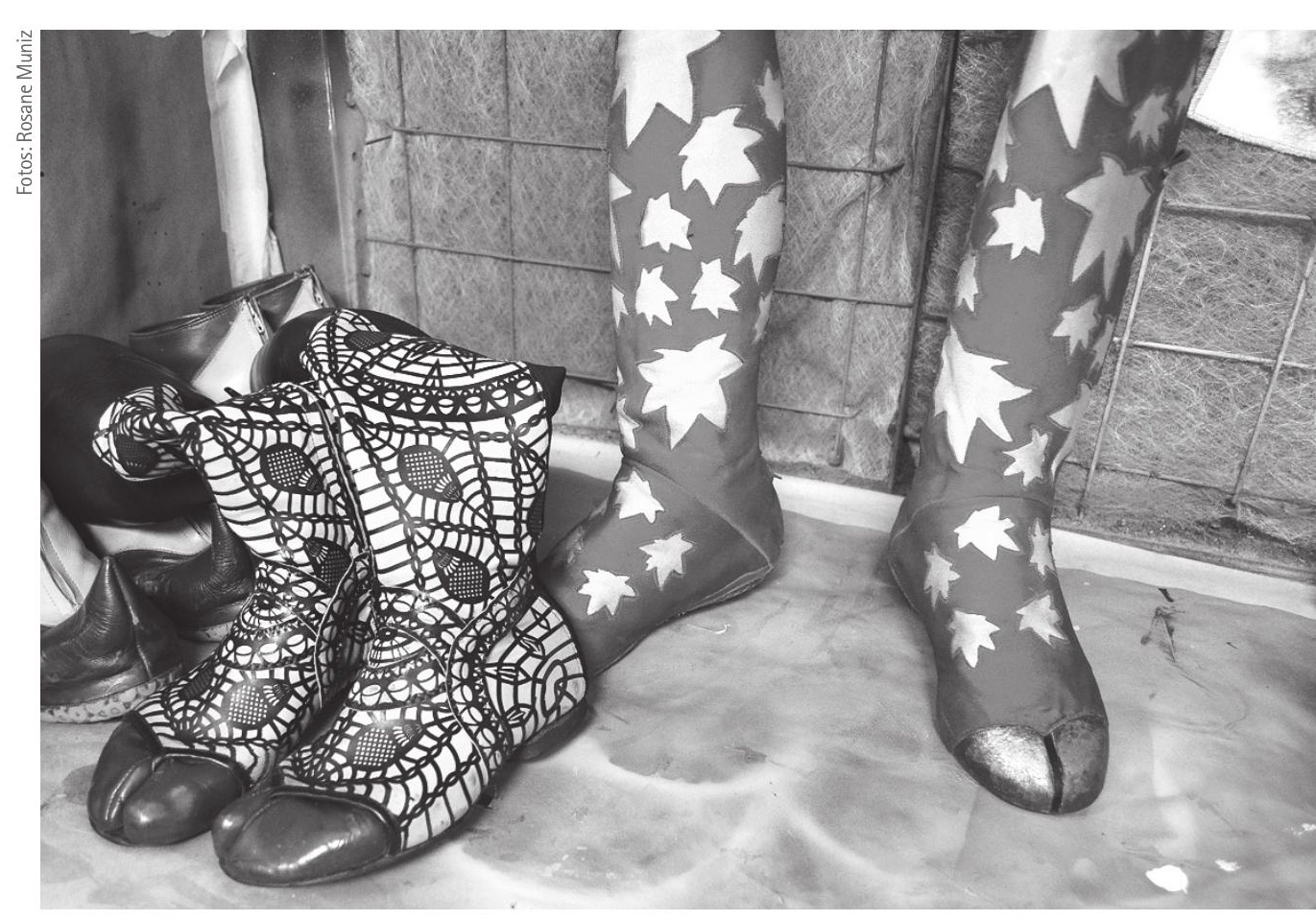

Oficina de $K \dot{A}$ para manutenção dos sapatos usados em cena e criados no ateliê central no Canadá.

O circo é o único lugar do mundo em que se pode sonhar com os olhos abertos.

Ernest Hemingway

0 trabalho do Cirque du Soleil é daqueles que metem medo de ir assistir pela primeira vez, afinal, somos "gente de teatro", e nosso maior dramaturgo deixava bem claro que "toda unanimidade é burra". 0 autor Nilton Bonder, em seu espetáculo filosófico A alma imoral, provoca a reflexão da plateia quando a protagonista diz que "a unanimidade expressa uma acomodação à verdade absoluta que é insuportável à vida e que tem grande potencial destrutivo". 0 tema também é a principal questão do famoso filme de Sidney Lumet 12 homens e uma sentença, como bem lembrou 0 jornalista Alessandro Martins. ${ }^{1}$ Ou seja, são no mínimo suspeitos todos os comentários positivos que ouvimos sobre as produções da trupe internacional. Conferimos algumas apresentações pela TV nos canais a cabo... No Natal, ganhamos um DVD do Cirque daquela tia que sabe que trabalhamos com teatro... Somos convidados por aqueles amigos que não gostam de teatro para assistirmos juntos ao Alegria, afinal, "não é 
bem assim"... (e olha que isso foi há muitos anos, antes do impressionante sucesso de "Para nooooossa alegria!") Por fim, somos bombardeados pela mídia, em outdoors, propagandas, entrevistas etc. etc. etc.

Afinal, o que há de tão grandioso por trás dessa criação circense? Acontece que o encontro da comissão de cenografia da Organização Internacional de Cenógrafos, Técnicos e Arquitetos de Teatro (OISTAT), da qual fazemos parte, este ano, foi em... Las Vegas, organizado com ajuda da Universidade de Nevada. Para abrir a primeira reunião, nada menos do que uma palestra com a diretora artística Ria Martens, do espetáculo $K \dot{A}$, do Cirque du Soleil. No dia seguinte, visita aos bastidores... Do Cirque du Soleil. Quatro noites livres... E o que acabamos por ver? Soleil, Soleil e Soleil, em três delas. São sete espetáculos em cartaz na cidade, com alguns dos teatros construídos em função da estrutura do grupo. Ingressos caros, teatros grandes, plateia lotada a cada sessão.

0 primeiro espetáculo, Le Grand Tour, foi em 1984, para celebrar $0450^{\circ}$ aniversário da descoberta do Canadá por Jacques Cartier. Máscaras de papier maché e trajes com base na inspiração militar e equestre conduziam a estética que apresentou o Cirque $d u$ Soleil nos seus primeiros três anos até a chegada do cenógrafo e figurinista canadense Michel Crête para Le Cirque Reinventè. Desde então, são mais de dez figurinistas, que vão de Dominique Lemieux, que realiza muitos estudos sobre os movimentos dos acrobatas e como as fibras reagem em contato com a pele, até Marie-Chantale Vaillancourt, parceira há anos de Robert Lepage. A trajetória da indumentária dos 25 anos da trupe, completados em 2009, foi registrada em uma exposição de figurinos e resultou no livro Cirque du Soleil: 25 years of costume, que é vendido nas lojas do grupo. Uma história que começa com 73 pessoas na fundação da marca e chega aos mais de 5.000 funcionários em todo o mundo, incluindo mais de 1.300 artistas. Só em Montreal, onde está a enorme sede da companhia, trabalham cerca de 2.000 funcionários. Os fundadores Guy Laliberté e Daniel Gauthier, dois ex-artistas de rua, em Québec, Canadá, e seus "olheiros" viajam pelo mundo testando novos talentos. São quase 50 nacionalidades, com 25 idiomas diferentes. Seus espectadores estão na casa dos mais de 100 milhões.

Antes mesmo de assistir a algum espetáculo do grupo internacional, começamos com a visita aos bastidores de $K \dot{A}{ }^{2}{ }^{2}$ Ao entrar no teatro, o diretor de produção conta a história do teatro, especialmente construído para suportar as necessidades técnicas do espetáculo. As cenas acontecem não só no palco frontal como em passarelas que ocupam tanto as laterais do palco como avançam por cima e ao redor de toda a plateia. Não conta quantos "milhões de dólares" gastaram na construção, mas mostra, orgulhoso, o palco central, que gira $360^{\circ}$ e pesa cerca de 36 mil quilos. Realmente, um aparato técnico "escandaloso" - no bom sentido, claro. 0s 80 atores atuam em várias cenas e usam de um a três figurinos, sendo que os performers mais experientes vestem até dez figurinos. As trocas são realizadas nos camarins mais próximos, apesar das coxias serem bem grandes para facilitar o trânsito dos 190 técnicos que trabalham nos bastidores durante o espetáculo.

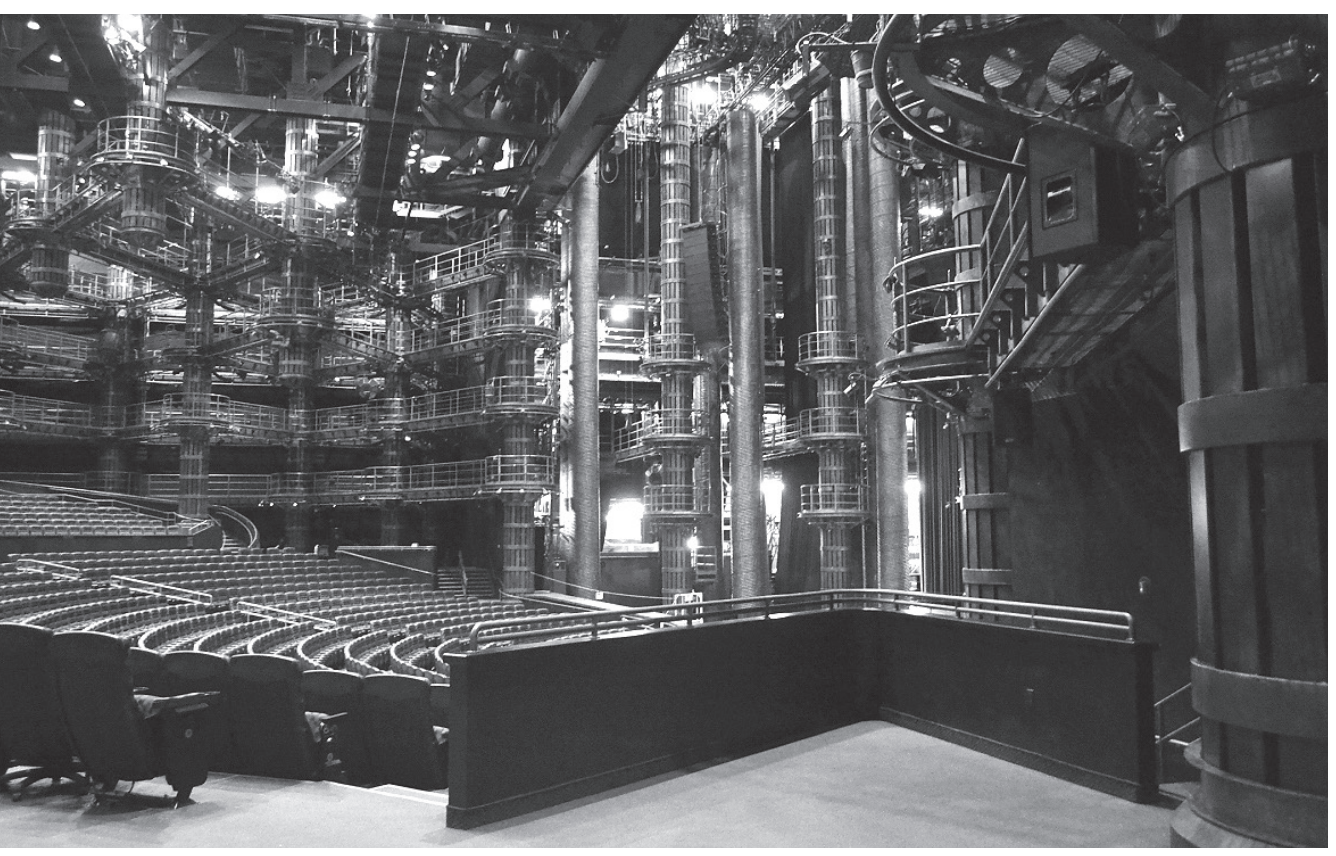

Visão geral do teatro construído especialmente para o espetáculo $K \dot{A}$, do Cirque du Soleil. 
Depois da coxia, onde visualizamos, na parte de baixo do palco, os colchões que amparam as várias quedas que acontecem ao longo de $K \dot{A}$, finalmente chegamos ao que interessa - o guarda-roupa - e somos recebidos pelo chefe Eric Wood. Aliás, é impressionante a rapidez com que eles manipulam os colchões de ar: levam somente 45 segundos para encher e subir cerca de 30 metros de altura, e 90 segundos para esvaziar. E haja costura para manter os figurinos em dia, com tantas manobras aéreas, mergulhos no vazio e peripécias nos palcos. Mas os figurinistas são especialistas e usam materiais que vão de tecidos e malhas a neoprene, látex, cabos de fibra óptica, linhas de pesca etc. Wood nos mostra alguns trajes que estão nos manequins e relata que são sempre muitas horas de trabalho até encontrar soluções técnicas que garantam 0 conforto e a segurança dos artistas. A lycra continua a ser um dos tecidos preferidos por suas características especiais de flexibilidade, elasticidade e longa duração.

Martens, em sua palestra, havia explicado que cada show leva cerca de três anos em fase de criação; sendo que um ano e meio se passa em conversas entre as diferentes equipes; nove meses para preparação e escolha do elenco, criação de figurinos, cenários, luz etc. e um mês de show para o público interno antes da estreia. Um ano depois, toda a equipe é chamada para conferir se tudo continua como criaram. Há um banco de dados de designers e diferentes profissionais que são escolhidos a cada trabalho de acordo com o estilo do novo projeto.

Cada figurino e aces-

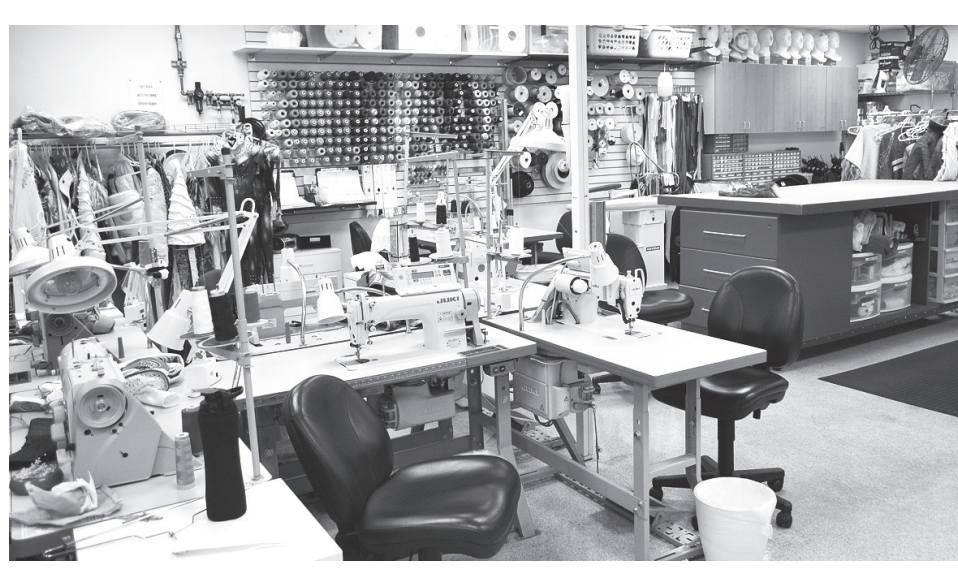

Guarda-roupa de $K \dot{A}$, com estrutura para ajustes e conservação dos trajes de cena. Ao fundo e no alto, alguns moldes das cabeças de cada performer para as provas de acessórios de cabeça.

sório é feito sob medida para cada artista. E todos os tipos de especialistas em suas áreas (sapatos, tecidos, chapéus, confecção de figurino, fabricação de rendas, marcenaria etc.) trabalham na sede internacional para desenvolver e produzir esses elementos. Os diversos ateliês contam com mais de 400 artesãos e já desenvolveram mais de 25.000 elementos para os mais de 20 espetáculos do Cirque du Soleil. A equipe responsável pelo design do figurino usa, anualmente, cerca de 130 quilômetros de tecidos variados, sendo que 80\% desses materiais são tratados e tingidos no local pela própria equipe de design têxtil.

Para não ser preciso comparecer a tantas provas de cabeças, perucas ou chapéus, cada ator tem sua cabeça reproduzida. Uma cabeça fica na sede da produção, em Montreal, e outra, nos camarins do espetáculo correspondente. A maquiagem dos artistas é feita pelos próprios, depois de muito treino, e leva entre 45 minutos e uma hora e meia para ficar pronta. No guarda-roupa, são gavetas e mais gavetas com produtos de várias cores da MAC. Wood conta que, nas trocas de roupa, também são realizados retoques na maquiagem, que, por ser feita à base de água, sai com facilidade e rapidez. Perambulamos por meio das araras, observamos gavetas, gavetinhas e uma organização admirável.

Uma organização que vem sendo implantada também em relação à conservação dos trajes. 0 acervo é tratado como Coleção Corporativa, que serve a um "propósito identitário", a Coleção Patrimônio de Figurino (Heritage Costume Collection). ${ }^{3}$ Exposições são constantemente organizadas na sede do grupo, afinal, a documentação por meio da fotografia foi descoberta como a melhor ferramenta de divulgação na campanha de coleta de figurinos junto aos chefes de guarda-roupas, cuja colaboração é crucial na busca e acesso dos figurinos aposentados. Em 2012, segundo Marie-Claire Dumoulin, técnica da Coleção, há 1.500 figurinos completos catalogados e mais de 1.000 à espera.

Este ano, no Brasil, está circulando por vários estados a exposição com alguns figurinos de Varekai, último espetáculo em cartaz no país. 0 título significa "onde quer que seja" na língua cigana e une duas histórias sobre a vida e seus prazeres. A primeira parte apresenta o mito de Ícaro, que tentou voar até o sol e teve suas asas derretidas. Quando ele cai dentro de um vulcão, começa a segunda parte, que é uma homenagem ao povo nômade, aos ciganos. Segundo o coordenador de comunicação do Cirque no Brasil, Ricardo Zonta, "os personagens são seres diferentes dos humanos, então, eles 
precisam ser diferenciados. 0 figurino tem muitas aplicações de espuma, tecidos que criam asas, penas, detalhes que descaracterizam o ser humano"4 e usa outros tipos de materiais, como aplicações em titânio flexível, esponja de náilon e alguns tipos resistentes ao fogo. Todos os trajes foram feitos por Eiko Ishioka, artista visual que morreu em janeiro deste ano, aos 74 anos.

0 figurino de Varekai foi a primeira experiência de Eiko Ishioka no mundo do circo. A figurinista já havia produzido peças para ópera, teatro e cinema, ganhando fama internacional após ganhar Oscar de melhor figurino por Drácula de Bram Stoker, dirigido por Francis Ford Coppola. Na produção para a trupe do Cirque du Soleil, ela teve que aliar sua originalidade com as dificuldades de se produzir uma peça com lycra, para que os artistas conseguissem realizar seus números. As cores e formas únicas de suas criações acentuam os movimentos dos artistas, maximizando-Ihes a beleza e a graciosidade. ${ }^{5}$

Para dar existência a esses seres imaginários, foram 600 peças entre roupas, chapéus, sapatos... As espumas aplicadas por baixo da seda expõem e salientam os músculos. São mais de 120 figurinos completos, sendo que cada um dos 58 artistas usa de quatro a cinco peças por espetáculo, que vão sendo substituídas de acordo com o desgaste, a cada três ou quatro meses. ${ }^{6}$ Para manter todo o guarda-roupa em boas condições durante as viagens de temporada, são necessárias cerca de 250 horas semanais de trabalho, com uma equipe constituída por 6 pessoas encarregadas do figurino para limpar, restaurar, engomar, retocar a pintura dos sapatos etc.

Finalmente, não há como terminar essa coluna de dObra[s] sem falar de Thierry Mugler. Em 2003, o estilista francês criou os trajes para o show Zumanity, um casamento entre o burlesco e o cabaré, explorando a sexualidade e a intimidade. Em cena, caudas longas, franjas, muitas plumas, vinil, couro, vestidos de veludo, corpetes finos, acessórios de plástico, mangas bufantes etc., difícil de imaginar em cenas da trupe circense. Mas Mugler sabe o que faz, afinal, dançou profissionalmente com a Ópera de Rhin desde os 14 anos. Escolheu trabalhar também com o látex e o metal não só pela aparência, mas pelo som que fazem, criando momentos de exuberante colorido, mas também "minimalistas", no branco e negro.

Guy Libertè exibia seu lado excêntrico, no início de carreira, como engolidor de fogo ou homem da perna de pau. Hoje, pode pagar 35 milhões de dólares para fazer marketing do espaço ao se tornar o sétimo turista espacial da história, o primeiro canadense, viajando por dez dias como parte da tripulação da missão Soyuz TMA-16, de onde anunciou que dirigia Da Terra às Estrelas pela Água, durante sua estada em órbita.

Excentricidade que é revelada em cada espetáculo, nos diferentes e múltiplos figurinos, assim como quando toneladas de areia escorrem do palco móvel de $K \dot{A}$ a cada apresentação e são filtradas por sistemas especialmente criados para o retorno aos reservatórios que as colocará à disposição da nova queda. Um enorme e caro aparato técnico a favor da visualidade. 0 contexto? Isso é o que menos importa, afinal, ali é um lugar para se sonhar, não para pensar...

\section{NOTAS}

${ }^{[1]}$ Disponivel em: <http://livroseafins.com>. Acesso em: 20 jul. 2012.

${ }^{\text {[2] }}$ Cenas do espetáculo $K A \dot{A}$ estão disponíveis em: <http://www.cirquedusoleil.com/en/shows/ka/default. aspx>. Acesso em: 15 maio 2012.

${ }^{[3]}$ Para saber mais sobre a coleção, leia os artigos A performance por detrás do palco: argumentos de uma coleção de figurinos circenses e Sob a luz do holofote: o papel da conservação de têxteis em um circo, apresentados pela Diretora Cultural da Coleção de Figurinos e Acessórios, Sylvie François, durante o Seminário Internacional, realizado no Museu Paulista da Universidade de São Paulo, entre os dias 8 e 13 de maio de 2006. In: PAULA, Teresa Cristina Toledo de (Org.). Tecidos e sua conservação no Brasil: museus e coleções. São Paulo: Museu Paulista da USP, 2006.

${ }^{[4]}$ Entrevista disponivel em: <http://redeglobo.globo.com/rs/rbstvrs/patrola/noticia/2012/07/dica-dopatrola-exposicao-mostra-figurinos-do-cirque-du-soleil.html>. Acesso em: 20 jul. 2012.

${ }^{[5]}$ Cirque du Soleil - Varekai - Figurinos. Guia da Semana. Disponivel em: <http://www.guiadasemana. com.br/artes-e-teatro/noticia/cirque-du-soleil-varekai-figurinos>. Acesso em: 15 maio 2012.

[6] EXPOSIÇ̃̃O mostra o figurino do Cirque du Soleil em Curitiba (PR). Disponível em: <http://noticias. r7.com/videos/exposicao-mostra-o-figurino-do-cirque-du-soleil-em-curitiba-pr-/idmedia/4fc7ea986b7 125d54da462ea.html >. Acesso em: 15 mai. 2012. 